\title{
16
}

\section{System For Preparing Management Decisions: A Gas pipeline siting case study}

\author{
O.I. Larichev, E.N.Andreyeva, M.Y. Sternin. \\ Institute for System Analysis \\ Russia,117312, Moscow, pr. 60 let Octjabrja, tel. (095)-135-85-03; \\ Fax : (095)-938-22-09 \\ E-mail: larichev@glas.apc.org
}

\begin{abstract}
The paper describes the analysis of an important problem: the choice of a gas pipeline route on the Yamal Peninsula in the North of Russia ${ }^{1}$. It is a real case of a difficult and controversial real-life decision. The authors were in the position of consultants, helping to decision makers to develop and justify a new and promising variant of the decision. The result of the utilization of verbal(categorical) decision analysis and a decision support system are given .
\end{abstract}

\section{Keywords}

Multicriteria choice, decision support system, active groups.

\section{INTRODUCTION}

The preparation of strategic and complex decisions is a long and time-consuming process. Two aspects are especially important: the exploration of the positions of different active groups participating in the solution of the problem and the invention of new, promising decision variants, acceptable to the problem to theactive parties.

The goal of the paper is to present a case-study describing the application of the DSS called ASTRIDA to the solution of a new and difficult problem in the development of the gas industry in Russia. This case involves major uncertainties and the necessity of making a difficult choice. We shall describe below the problem and our experience in applying the DSS.

1 The research is partly supported by the Russian Fund for Fundamental Research N 95-01-00083 and NSF grant DPP9213392. 


\section{BACKGROUND}

According to expert estimations, gas extraction in Russia will decrease in the next few years. To compensate for this reduction and to keep the gas supply to Europe, the Government of Russia is pushing the exploration of new gas fields. The Northern regions of West Siberia are famous for the great deposits of natural gas discovered there during the last 10-15 years. The most outstanding gas fields, with reserves of more than 20 trillion cubic meters, are situated on Yamal Peninsula, which has severe climatic conditions and a vast expanse of permafrost soils.

For the Central Government of Russia and the institutions responsible for energy, the issue of gas development on the Yamal peninsula is clear: the resources should be developed. The logic of such a decision is easy to understand: gas reserves elsewhere are exhausted and gas exports can noticeably increase Russia's national income. There are many unsolved problems within the framework of the initial decisions on Yamal development. One of the most essential is the choice of route for that part of the gas pipeline from the gas fields to the existing gas pipeline system. During the elaboration of the gas pipeline project, the idea of straightening the pipeline received strong support. The point was to make the line shorter by crossing the Baidaratskaya Bay, an inlet of the Kara sea. A second land-based option would cross the Yamal Peninsula to the east of Baidaratskaya Bay. The choice of option has been the subject of bitter discussion between two institutes involved in the project during the last two years. Both have arguments for and against the sea and land routes. The decision point and the start of pipeline construction has been recently postponed, partly due to the complexity of this choice.

Thus the task addressed here is one of decision-making with two alternatives. As we shall see, this problem concerns the interests of various different groups who are able to influence the choice. It also depends on unknown natural conditions, and on contradictory appraisals of the alternatives on various criteria, etc. In the following, we consider these options in detail.

\section{TWO OPTIONS}

The two options are: a sea route, crossing the Bay, and a land route. The following distinguishing characteristics have been included in analysis: 1 . Length of the route. The sea option is shorter than land route. 2. Terms of construction. The conditions of construction are very difficult for both options: a large expanse of permafrost and enormous rivers and lakes. But there is an essential difference: the need to cross the bay (about $68 \mathrm{~km}$ length). 3 . Time for construction. Construction for both the options depends on how the work is organized. There is no appropriate technology in Russia for pipeline construction at the bottom of the sea. Some foreign firms have offered their help in constructing the sea segment of the pipeline. 4. Cost of construction. This factor is of great importance but very difficult to estimate. In principle, it is possible to evaluate the cost of the land route from knowledge of the necessary quantity and prices of tubes for pipeline, technological and building equipment, fuel and labor cost. 5 . Impact on the environment. As noted above, the land route will cross many ecologically valuable areas, including reindeer pastures, wildlife refuge, 
hunting lands as well as rivers and lakes famous for their very high productivity and fishing resources. 6. Risk of pipeline rupture accidents. The probability of a land route accident may be assessed on the basis of existing data on pipeline operations in the North. Statistical information on gas pipe line accidents in mountain regions can help to make this assessment more precise and adapted to the Polar Ural region. On the other hand, risk assessment for the sea route is rather difficult. World experience includes no statistic data on the operation of an underwater pipeline under such severe arctic conditions. The situation with Baidaratskaya Bay is unique with specific features which could cause an accident. Namely:

- instability of the shore sites with permafrost processes and impact of sea ice.

- rupture of or damage to of the pipeline by underwater ice.

- experts on ice conditions in the Kara sea confirm the probable appearance of iceberg sections capable of reaching Baidaratskaya Bay.

7. Consequences of pipeline rupture accidents. In the land route case an accident on the pipeline is associated with explosion and fire. As a result, the impact on the natural environment is very high: complete destruction of the vegetation cover and thermal regime of permafrost soils, and the death of all wild animals. An underwater accident has less environmental impact: the gas will dissolve in water and is not toxic. The ice cover is not solid and gas can come out through cracks into the atmosphere. 8. Time to recover from accident. This factor determines gas supply reliability. There is much experience of repair operations in the case of land laid pipelines in the Russian North. As for the underwater part of the sea option, repair of a destroyed segment is limited to the 2-2.5 months a year when the Bay is free of ice. Furthermore these operations require special techniques and equipment (barge, caisson apparatus, etc.) 9. Uncertain and unknown factors. Any choice of option has some circumstancesabout which not enough is known at the time of decision-making. Most of these unknown factors would need long-term observations and prolonged investment in scientific research before uncertainty about them could be reduced. Thus, the decision must be made under conditions of major uncertainty, given that the construction start date has been set in the immediate future.

\section{ACTIVE GROUPS}

Before comparing the two options we must analyse who will make the choice and how. It is not likely that the choice of option will be made by a single decision-maker, because of the high cost of this project. On the contrary, several institutions and organization are taking part directly or indirectly in the decision. We will call them the "active groups". They are the following:

1. Russian joint stock company "Gasprom" (RAO Gasprom), which ordered the development of the project, and will evaluate and confirm it.

2. The two project research institutes who developed the two options (sea route and roundabout land route): each institute supports a different option.

3. Nadymgasprom - the operational division of RAO Gasprom in the North Siberia region, which is responsible for the construction and exploitation of the gas pipeline system. 
4. Ministry of Economy - evaluates the economic considerations and economic efficiency of future project, and approves the design.

5. Ministry of protection of environment and natural resources - evaluates the ecological impact and ecological security of the project, gives the permit for construction.

6. Local authorities in the Yamal region, who must give their agreement to one option for the pipeline.

7. Local communities (or representatives of native peoples), whose territory and resources will be impacted by the construction of a very large pipeline system.

The active groups have different motivations concerning the choice in question. Actually we face different orientations and contradictory opinion towards the criteria. One might expect that they would support different options.

To understand better the attitude of all the active groups in this great project, it is worthwhile noting that the idea of its development appeared more than 15 years ago. During the intervening period much has happened in the life of Russian society: transformation from centralized governance and planning to new market relations accompanied by high inflation, assessment of the efficiency of the northern mining and oil activities under new economic conditions, establishment of new relations between federal and regional authorities, increase of the role of local communities in the decision-making regarding the use of resources or territories which traditionally were inhabited by the people of these communities. All these factors impacted on the opinions of the active groups involved in this project of exploration of Russia's richest gas reserves in the most complex geographic region, famous for its strong traditional economy of yamal-nenetz people based on biological resources.

All the societal processes in Russia were still in flux while the situation with Yamal project started up very rapidly in 1984 but was frozen after 1989 for a while. The freeze was connected with very strong opposition to the operational activity of the construction firms from local authorities, from the indiginous people of the peninsula and from a group of scientists - members of National Commission of Experts who made the evaluation of the feasibility study: the basic document for this development.

The leadership of the RAO Gasprom had to agree to the temporary suspension of the activity at the peninsula in accordance with the commission's conclusions. It had become clear that there were too many unsolved technical and environmental problems which couldn't be avoided or neglected: they required fundamentally new decisions. Among those problems was that of the choice of the main pipeline route from the mother gas fields Bovanenkovo-Harasavey to the European part of Russia and western countries.

First the experts of the RAO Gasprom submitted for consideration 6 different routes, which combined some options for routes through land and sea. After long discussions in which many specialists were involved (in accounting for all expenditures, assessing of advantages and disadvantages of each route, etc.) only two options were left: the short route involving the crossing of Baydaratzkaya Bay and a longer route, taking a roundabout way, crossing the western part of Yamal peninsula and Polar Ural.

Each route crossed very complex sites and needed additional investigations under field conditions. It was necessary to determine which industrial company (Russian or foreign) would be able to carry out this work. During the initial discussions of the two options, the 
leadership of RAO Gasprom had already stated its preference in favor of the sea route. The process of searching for a foreign company who could take on the laying of pipeline on the sea bottom was already very active while the preparation of the feasibility study was only just getting underway.

Nevertheless, a serious investigation, involving the comparison of the two options, had to be made. This work had been entrusted to two project design institutes which already had considerable experience in the development of pipeline systems in Western Siberia. One of them, GIPROSPECGAS (St.Petersburg), started first and from the very beginning was a strong supporter of the land route. The staff of the Institute conducted investigations comparing the two options and confirmed again that the land route was more preferable.

In explaining this choice they gave the following arguments. There are no firms in Russia, not even in the world, who have experience in construction of gas pipelines under such complex permafrost conditions and under the persistent impact of active sea ice. This option needs special and very expensive equipment for working in the sea the while Russia has a difficult financial situation and it would mean creating new debts to foreign countries.

The risk of accidents during exploitation of the pipeline system is very high while the period for repair works is limited by the period of only three to four months of open water in Baydaratzkaya Bay. This factor reduces the general reliability of the gas supply system.

As for the land route option, any breakdown of the pipeline could be restored within 72 hours regardless of the season and using only domestic technical means.

The other institute, YUSNIIPROGAS (in Donetzk), is a supporter of sea route and made its own comparison of the two options. They accepted the concern that sea route needs a quite new technology for pipe laying (the depths of the bay varies from 6 to 29 metres), has many uncertainties which are usual for the Arctic. But Russia is opening a new stage of gas field development - in the exploration of the arctic shelf zone. So it is high time to begin to obtain some new experience - new for the whole world - and thus to be ahead. This idea was very popular among the leaders of RAO Gasprom and very soon this Institute received the leading position in the development of this project. As a foreign partner, the Dutch company "Haarema" was selected to construct the first two lines of the underwater part of the pipeline system.

The feasibility study was ready in summer 1994, but the start of the construction depends on the readiness of other parts of the project - preparation of gas fields for exploitation, not to mention the financial and organizational problems. It is worth noting that the famous and very powerful Ministry of Pipeline Construction, which had previously existed in the Soviet Union and which provided the resources for creating numerous pipelines all over the country, had now been transformed into several holding companies. This means that now there is no single strong construction company which could carry out the whole range of construction works. RAO Gasprom has to deal each time with a different company regarding different parts of the whole project. Also, the extraordinary permafrost conditions required additional experiments searching for quite new technological solutions. This work is not finished yet.

Throughout all this period RAO Gasprom, the final decision-maker, returned back to the two options for the Yamal gas pipeline route many times and in spite of contradictory views, stuck to the sea route. Moreover, the Board of Directors examing the feasibility study made by YUSNIIPROGAS in 1994, came to the final conclusion that the sea route was the only 
acceptable option. The complex situation in regard to energy policy in Russia nevertheless didn't change the attitude to natural gas as priority number one in the fuel balance. But the attitude to different gas fields changed, depending on the readiness of technological decisions, success in cooperation with foreign companies and the investment climate. Due to these factors, preference in time of development was given to gas-condensate and gas-oil fields located in the shelf of Barentz sea, while Yamal gas fields were supposed to be involved in activity afterwards. It was reported recently by officials of RAO Gasprom that the start of the construction of the Yamal gas pipeline system has been postponed until 1997, while the preparation works in the Pechora sea and adjacent coastal zone are already under way.

Another active group, Nadymgasprom (a division of RAO Gasprom in Western Siberia), was in charge of realising the plans to develop the most Far North gasfields in the Yamal Peninsula. During the period of preparation for exploration, this organization is monitoring the field work which has been conducted specifically to increase knowledge about the geographical and engineering peculiarities of the future construction under severe arctic conditions. It is clear that the political strategy of this department reflects the attitude of its patron organization, RAO Gasprom, although, as a technical executive division, it has its own interests related to enhancing its influence in the region, the more complete use of the personnel at its disposal (they had to cut back operational works in accordance with general decrease of activities of the gas industry during the last period).

Therefore this active group is interested in speeding up the start of development, but the land route provides more employment with the use of domestic experience in pipeline construction in permafrost regions, including laying pipes on the bottom of the $\mathrm{Ob}$ river.

A new active group, which began to take part in the decision-making process only during the last 8-10 years, comprises the local communities of the indiginous population, more precisely, representatives of them in local administrations or regional associations. For the Yamal peninsula, the relevant organization is a regional association called "Yamal - for future generations". Since the beginning of the geological and other exploration activity, this group has been in strong opposition to the industrial development of the territory. It is worth noting that the yamal-nenetz ethnic group is rather stable and is well versed in social and political science. It had a well developed traditional economy based on reindeer breeding, commercial and domestic fishing, hunting on land and marine wild animals.

The ecological state of the territory where the yamal-nenetz group lived traditionally for many centuries is a crucial factor in their survival and development as an ethos in the future. Namely, these territories appeared to be under obvious ecological danger from the large scale development of gas deposits, construction of many engineering projects, of a railroad and a pipeline system. The methods of industrial development employed in other places in the North-West of Siberia have demonstrated its destructive character from the ecological point of view, and the danger for northern yamal-nenetz population has actually become obvious. They have started a long and hard struggle for their rights, which is continuing up till now.

The transformation of the northern traditional economy is proving to be particularly painful and difficult. The need to resist waves of Russian unstable conditions and maintain market requirements, placed the local communities, with their low profit branches of the economy, in particularly hard situation. Most of the collective farms are in a state of decay, new individually owned farms try to find their way in this cruel financial world, many people have 
lost their jobs and even the very low income they had before. The perspective of the new events, related to gas development, became a new alternative which could impact on their life, not only in a bad way, but perhaps which could offer some new opportunities.

RAO Gasprom tried to use this mood of change in its own interest, making a very successful attempt to change the general negative attitude of the indiginous population regarding industrial development. The aboriginal population was given an opportunity to be an active participant in this development, distributing shares of the new objects within the local communities, with preferencial treatment for indiginous people. This measure actually had a positive effect and there are a lot of people who now support the Yamal gas development project as offering a new hope for this administrative region. The delay in the start of the construction is a question of even more vital interest than the question of development itself. Nevertheless, the indiginous people have more real imagination about their rights and the responsibilities of "developers" so this problem of mutual understanding is not simple and needs more time to form a compromise in the decision-making.

The obligatory participant in this decision-making game is the State Ministry for Natural Resources and Protection of the Environment. Its role is rather standard: to make an assessment of the future impact of the project on the environment and to give the permit, or not, for its realization. This Ministry had rejected the Yamal feasibility study in 1989. although the new (corrected) variant of the feasibility study on the construction of the main pipeline system from Yamal to the Centre is ready, it has not yet been submitted to the Ministry for consideration. This will be the final decision-making step before the actual action, so RAO Gasprom will try to do its best to avoid a new failure. In December 1995 a new State Law on ecological expertise was passed in the Russian parliament (the State Duma) which further strengthens the position of this Ministry in its relationship with the Government Departments for industrial branches of the economy.

\section{5} THE EVALUATION OF OPTIONS

Many reports were prepared by the two project organizations, containing calculations based on different models and assumptions. Those reports were taken as the base for the analysis given in the paper. Let us note that the evaluations of options on criteria given by the two organizations are different and sometimes contradictory. The analysis was done for RAO Gasprom by a team from the Russian Institute for Systems Analysis including the present authors.

Multi-criteria utility theory requires deterministic or probabilistic evaluations of options. But how could we get them in this case? We look at the options through "a fog of uncertainty" deriving partly from the difficulty of measuring options in terms of the criteria. How could we evaluate the cost in a period of massive inflation? How could we compare the probability of an accident in the absence of information, reliable models or data of long-term observations?

The essential difference between the options consists in crossing the Baidaratskaya Bay (option A) and in the construction of an additional $160 \mathrm{~km}$. of pipeline (option B). It is logical to take into account only the criteria where we can find an essential difference between the options in terms of those criteria. In other words, we take criteria where one can see 
something really different through "the fog of uncertainty". For example, the preliminary estimation shows that the time required is 5-7 years for both options. The unstable internal economic situation can impact on the starting time.

1. Cost. The cost of crossing Baidaratskaya Bay (Ca) is determined by a foreign firm which is ready to construct this part of the pipeline. The initial approximate estimations show that the cost of option A is a little bigger than the cost of option B.

2. Ecological impact. Both options have a negative impact on the environment. But for option B this influence is much larger: it occupies a lot of land and crosses many rivers, though there is some uncertainty about the influence of option A on marine life.

3. Probability of accident. Due to unstable shores and heavy blocks of undersea ice the probability of an accident is larger for option A.

4. Consequences of the accident. In the case of option $B$, an accident is usually connected with an explosion and destruction of the environment. In the case of option $A$, there would not be an explosion. The gas would rise through the water and cracks in the ice. Option B is clearly worse.

5. Reliability of gas supply. The repair of the pipeline after an accident requires much more time for option A, particularly since the bay is free from ice only 60-70 days per year. Option A is clearly worse.

6. Uncertain and unknown factors. There are many uncertain and unknown factors connected with the realization of the unique project of crossing the Baidaratskaya Bay. Option A is clearly worse.

So, we have the comparative evaluations of options in the qualitative form. These are practically all that we can measure. It is difficult to get more than comparative measurements. How could we draw conclusions with such weak measurements?

\section{THE COMPARISON OF TWO OPTIONS}

In the framework of categorical or verbal decision analysis (Larichev, 1987,1992) special methods for comparison of alternatives described in terms of verbal evaluations upon criteria have been developed (Moshkovich,1991; Berkeley et al., 1990; Larichev and Moshkovich, 1996). One of these is the method of pair-wise compensation. In using this method, one is trying to find a condition when the disadvantages of one option are dominated by the disadvantages of the other.

First, the decision maker ranks the disadvantages of two options separately. In our case he or she ranks the disadvantages of Options A and B from the point of view of his or her preferences. Then, special "reference options" are created, which are constructed from real ones in the following way: each has the best (or worst) evaluations of two options on all criteria, except for one or two on which real disadvantages are given. When comparing the two reference options, the decision maker finds the partial compensation of some disadvantages of one alternative by the disadvantages of the other one. If it is possible to find such compensation for all disadvantages of one alternative the problem is solved. When comparing 
the two reference options, the decision maker performs a psychologically valid operation involving the comparison of two objects which differ only on two or three criteria (Larichev, 1992). It is possible to prove (Moshkovich, 1991) that the operation of the compensation is mathematically true in the condition of preference independence (Keeney and Raiffa,1976). The check of the condition of preference independence is the coincidence of results of comparisons for two pairs of reference options which differ only in best or worst evaluations on all criteria except one or two (on which real disadvantages are given ).

But it is not always possible to find pair-wise compensation of disadvantages of two alternatives. By making only qualitative comparisons, one can receive noncomparability, when some evaluations are better for the first option and some better for the second, which was the case in the comparison of the two options for Yamal pipeline. The greater uncertainty and lower reliability of gas supply for option A are worse than ecological impact for option B. But the negative consequences of an accident for option $B$ is worse than the larger probability of an accident for option A. In such case it is necessary to undertake an attempt to develop a new, more promising option on the base of existing ones.

\section{THE DEVELOPMENT OF A NEW OPTION}

In this case, as in many others, the practical value of decision analysis consist not only in the comparison of existing options, but in the creative invention of new ones. A method for aiding strategic choice, ASTRIDA (Berkeley et al., 1991) has been developed which permits not only the comparison of several options, but also the definition of the requirements of a new, desirable and potentially best option. ASTRIDA uses verbal evaluations of the options on each criterion, and calls for the decision-maker to make pair-wise comparisons. Such comparisons can be made from the points of view of different active groups. We shall give below the analysis corresponding to the interests of RAO Gasprom.

In the case of incomparability, the method ASTRIDA proposes is to make a modification of one existing option. That is, the method asks the question: what needs to be changed in one option to make it equal to or better than the other option? Thus, ASTRIDA defines the characteristics of a potentially best option that was not initially on the original list of preferred alternatives.

A new sea route option resulted from a search for ways to change these characteristics. (Larichev et al., 1995). Discussions with the experts suggested ways in which the negative comparisons of the sea option could be removed:

- To eliminate the influence of seashore instability, special shafts could be constructed at a safe distance from the sea, and the pipeline put through them. This construction will incur additional costs: $C$ shafts.

- To avoid damage to the pipeline from ice scouring, the pipeline can be laid in special trenches 1.5 - 2 meters deep. They would be deeper than the project plan calls for, so the costs, Ctrenches, will also be additional.

- Icebergs are a very rare but dangerous event in the bay. A special observation service and a special ship to drag the iceberg away would eliminate this problem. Let us denote the cost of the service and ship by Cice. 
Adding these features to the old sea alternative creates a new option with an element of uncertainty approximately equal to the traditional land option. The probability of an accident for the new sea option is not very different from that for the land option. With the development of a special repair service for the underwater tubes, the reliability of the gas supply could be made equal. Thus, no significant differences now exist between the sea and land routes, except cost and ecological impact. The cost of the new sea option, Csea + Cshaft + Ctrenches + Cice, will clearly be more expensive. The land option will still create greater environmental destruction. Now the comparison can be considered as one between higher costs and better environmental protection.

\section{THE ANALYSIS FROM THE POSITIONS OF THE ACTIVE GROUPS}

The analogical analysis was made from the positions of the active groups. The development of the new option was useful in this case too. Concerning the two initial options only, the positions of the local authorities and the local population were clear: they supported the sea option. (the projects research institutes obviously supported the options developed by them). The new sea option was more attractive for the Ministry of Ecology and Nadymgasprom. The positions of RAO Gasprom and the Ministry of Economy in the final, crucial choice presented above were influenced by the financial situation in Russia. In recent years this situation has been rather difficult.

\section{THE INFLUENCE OF RECOMMENDATIONS}

The report, with the recommendations presented above, was given to RAO Gasprom. At that moment the first sea option was the more attractive one for the majority of managers. That why they were expecting that analytical report prepared by the consultants from Institute for Systems Analysis would be positive on this option. But the report created doubts about the possibility of acceptance of this option. At that moment the intention to begin the construction of the pipeline was strong enough.

In spite of the government's desire to make practical steps in regard to pipeline construction, there were some grounds for postponing this decision. We can say that one of them was the uncertain and unknown factors shown by the report. There was an objective conformation of this fact: during the delay in the beginning of construction, new investigations were undertaken on the problem of instability of the seashore that was presented in our report.

Recently the start of the Yamal pipeline construction was postponed yet again due to several important factors. From our point of view, the most important one is the uncertainty in the problems connected with the conditions of the construction. Unfortunately, it is impossible to remove this uncertainty completely. That is why the next decision (based on new data) is to be taken again under conditions of uncertainty.

Uncertainty exists in either option. That is why consideration must be given only to the factors for which essential differences truly exist. In other words, we must look at only the bright lines and broad brush strokes. The decision analyst tries to reduce the problem to one 
where the crucial choice could be evident. In our case, the comparisons of two options (land option and new sea option ) revealed the necessity of crucial choice between the great cost of the construction of a safe pipeline in the difficult Arctic conditions and the huge damage to the unique nature of Yamal. The value of the analysis consists in the possibility to help people (decision makers and experts) to develop a new, promising decision variant which could be the best one under some conditions.

\section{CONCLUSION}

The implementation of the results of the analysis required repeated meetings with experts and decision makers. The questions discussed were very sensitive from organizational point of view due to necessity to begin the pipeline construction. But finally a delay was accepted in order to study in detail the main sources of uncertainty indicated by the analysis. For the analysts this was a demonstration of the influence of the analysis on real decisions.

\section{REFERENCES}

Berkeley D., Humphreys P., Larichev O., and Moshkovich H. (1991) Aiding Strategic Decision Making: Derivation and Development of ASTRIDA. In Environments for Supporting Decision Processes (Eds. J. Vecsenyi and H. G. Sol), North Holland, Amsterdam

Larichev O., Brown R., Andreyeva E., and Flanders N. (1995) Categorical decision analysis for environmental management: a Siberian gas distributing case. In Contributions to Decision Making (Eds. J.-P.Caverni, M. Bar-Hillel, F.H. Barron \& H. Jungermann), North Holland, Amsterdam

Larichev, O. (1992) Cognitive validity in design of decision-aiding techniques. Journal of Multi-Criteria Decision Analysis 1, 127-138.

Larichev O. (1987) Objective models and subjective decisions. Nauka Publishing House, Moscow. (in Russian ).

Larichev O. and Moshkovich H. (1996) Qualitative methods of decision making. Physmatlit Publishing House, Moscow. (in Russian ).

Moshkovich H. (1991) Qualitative methods in multiattribute decision making. Proceedings of 13th Research Conference on Subjective Probability, Utility and Decision Making, University of Fribourg, Switzerland.

\section{BIOGRAPHY}

Professor O. Larichev is head of a department of the Institute for System Analysis of Russian Academy of Sciences. His fields of interest are psychology, decision making, multicriterial mathematical programming, decision analysis, nonlinear programming. He is an author of seven books and 170 papers in the fields of decision making and artificial intelligence. 
Doctor E. Andreeva is the leader of the Geoinformational and Analytical Centre of the Russian North, Institute for System Analysis of Russian Academy of Sciences. Fields of interest are resource and environment management in the Arctic and the North; Impact of oil and gas industry on ecological and social system. Dr. Andreeva is an author of one book and 45 papers in the fields regional policy in the North, analysis of ecological and social consequences of the industrial activity in polar regions.

Michael Sternin is a senior scientific researcher in the Decision Support System department of the Institute for System Analysis of Russian Academy of Sciences. His field of interest is Decision support systems. He is an author of 35 papers in various areas of the field of decision making 